\title{
Zn(II)-catalyzed Rearrangement of Epoxides Using an Ionic Liquid
}

\author{
Nan Hee Ko, Hoon Sik Kim, Sang Ook Kang, ${ }^{\dagger}$ and Minserk Cheong ${ }^{\circ}$ \\ Department of Chemistry and Research Institute for Basic Sciences. Kvang Hee Universitv. Seoul 130-701. Korea \\ "E-mail: mcheongia \\ ${ }^{\dagger}$ Department of Chemistry, Korea Unwersity, Chochin'on, Ching-nam 339-700, Korea \\ Received December 19, 2007
}

Key Words : Stilbene oxide. Rearrangement, Deoxybenzoin Ionic liquid. Zinc catalyst

The opening of epoxide rings catalyzed by $\mathrm{Zn}$ (II) has been studied by many scientists since it is the first step in the carboxylation of epoxides to carbonates. ${ }^{l}$ Several catalytic systems. such as Bronsted or Lewis acids. "lithium salts. ${ }^{3}$ $\mathrm{MgBr}_{2}{ }^{4} \mathrm{Pd}$ complex. ${ }^{5} \operatorname{InCl}_{3}{ }^{6} \operatorname{IrCl}_{3} \cdot n \mathrm{H}_{2} \mathrm{O}^{7} \operatorname{Er}(\mathrm{OTf})_{3 .}{ }^{8}$ $\mathrm{Sn}(\mathrm{OTF})_{2}^{9}$ or $\mathrm{BiOClO}_{4}{ }^{16}$ have been developed for the rearrangement of epoxides to carbonyl compounds. However. there has been little success in the selective rearrangement of epoxides. being plagued by the fomation of by products and low yield.

In studying the carboxylation of sterically hindered epoxides. we have found that in the absence of carbon dioxide these epoxides rearranges to carbonyl compounds. For example trans-stilbene oxide is rearranged to deoxybenzoin selectively' while cis-stilbene oxide is not reactive under our reaction conditions. Since there has been no report using $\mathrm{Zn}$ (II) with ionic liquid for the rearrangement of epoxides. our syystem seems to be quite interesting in two aspects: (1) Only one isomer. trans-stilbene oxide is reactive under our reaction conditions. (2) Only one rearrangement product. deoxybenzoin. is obtained selectively:
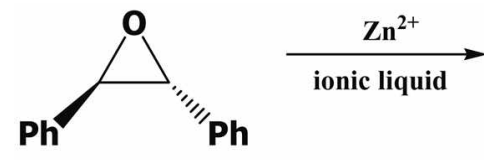<smiles>O=C(Cc1ccccc1)c1ccccc1</smiles>

In this paper. we report our results on the use of imidazolium-based ionic liquids with $\mathrm{Zn}(\mathrm{II})$ for the rearrangement of epoxides as well as theoretical investigation of these reactions.

1-Decyl-2.3-dimethylimidazolium iodide. ([DDMLm]I) was prepared by reacting methyl iodide with 1-decyl-2.3dimethylimidazole. Irons- and cis-stilbene oxides were prepared by reacting corresponding stilbene with $m$-CPBA under $\mathrm{N}_{2}$ in dichloromethane. After workup with $\mathrm{NaHCO}_{3}$ and further purification with column chromatography. the product was obtained as a pure solid. Rearrangement reaction was carried out by contacting stilbene oxide with [DDMIm] I and $\mathrm{ZnI}_{2}$ in $10 \mathrm{~mL}$ of $\mathrm{N}$-methylpy'rrolidinone (NMP) in a high-pressure stainless steel bomb reactor. The reaction proceeded cleanly without producing any side product except where it was noted in the Table 1. Typical side products of the product were identified as diphenyl
Table 1. Rearrangement of trans-stilbene oxide in NMP at $120^{\circ} \mathrm{C}$

\begin{tabular}{cccccc}
\hline entry & $\begin{array}{c}\text { trans-stilbene } \\
\text { oxide (mmol) }\end{array}$ & $\begin{array}{c}\text { [DDMm)I } \\
(\mathrm{mmol})\end{array}$ & $\begin{array}{c}\mathrm{ZnI}_{2} \\
(\mathrm{mmol})\end{array}$ & $\begin{array}{c}\text { reaction } \\
\text { time }(\mathrm{h})\end{array}$ & $\begin{array}{c}y \text { ield } \\
(\%)^{4}\end{array}$ \\
\hline 1 & 19.0 & 1.25 & 0.03 & 6 & 10 \\
2 & 19.0 & 1.25 & 0.03 & 15 & 48 \\
3 & 19.0 & 1.25 & 0.03 & 24 & 60 \\
4 & 19.0 & 0 & 0 & 15 & $7.1(6.0)^{b}$ \\
5 & 19.0 & 1.25 & 0 & 15 & $17(14)^{b}$ \\
6 & 9.5 & 1.25 & 0.03 & 15 & 67 \\
7 & 9.5 & 1.25 & 0.06 & 15 & 100 \\
8 & 9.5 & 0.625 & 0.06 & 15 & 40 \\
9 & 9.5 & 1.875 & 0.03 & 15 & 91 \\
\hline
\end{tabular}

${ }^{a}$ The rields were detemined by NMR based on the area ratio between the product and the reactant since there is no other species present. ${ }^{b}$ Side products were produced. The yield of the side products is shown in the parenthesis.

acetaldehy'de and benzophenone by NMR and GC-MSD analysis. These are known to be produced via uncatalyzed thermal radical process.

[DDMIm]I was chosen as an ionic liquid for the reaction since it was most stable under our reaction conditions among various ionic liquid we tested. Table 1 shows the results of the rearrangement of stilbene oxide catalyzed by $\mathrm{Zn}(\mathrm{II})$ and ionic liquid [DDMIm]I.

The yield increased as the increase of the reaction time (entry 1-3). Without [DDMIm] I and $\mathrm{Zn}$ (II). the reaction was very slow also producing side products (entry 4). With [DDMLI] I alone the reaction was still slow (entry 5). Only with the co-presence of both $\mathrm{Zn}(\mathrm{II})$ and [DDMIm] I. the reaction goes to completion (entry 7). The reaction rate is strongly dependent on the concentrations of $\mathrm{Zn}$ (II) (entry 6 . 7) and [DDMIm] I (entry 7.8 or entry 6.9).

Rearrangements of other epoxides were also studied and shown in Table 2. Trans-stilbene oxide was found to rearrange to deoxybenzoin. whereas cis-stilbene oxide was not under the same reaction condition (entry 1-2). The reaction rate increased significantly when a phenyl group of stilbene oxide was replaced by a methyl group (entry 3 ). The reaction rate was accelerated further when both phenyl groups were substituted by methyl groups. resulting in conversion of 2.3 -dimethyl oxirane even at $80^{\circ} \mathrm{C}$ (entry 4) where trans-stilbene oxide is unreactive (entry 5 ).

The stability of $\mathrm{Zn}(\mathrm{II})$ complexes with stilbene oxides and 


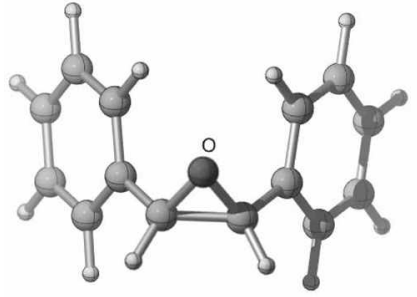

1

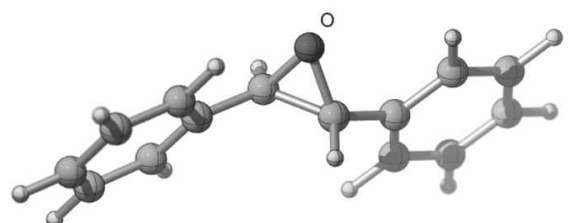

2

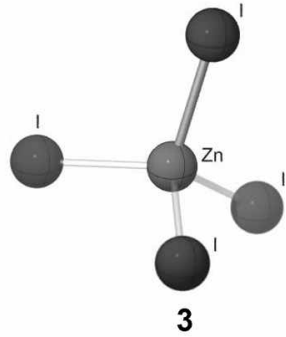

3

Figure 1. Optimized structures of reactants.

Table 2. Rearrangement of other epoxides in NMP"

\begin{tabular}{ccccc}
\hline entry & eposide & $\begin{array}{c}\text { temperature } \\
\left({ }^{\circ} \mathrm{C}\right)\end{array}$ & $\begin{array}{c}\text { reaction } \\
\text { time }(\mathrm{h})\end{array}$ & $\begin{array}{c}\text { yield } \\
(\%)\end{array}$ \\
\hline 1 & cis-stilbene oxide & 120 & 15 & 0 \\
2 & trans-stilbene oxide & 120 & 15 & 67 \\
3 & 2 -methyl-3-phenyl oxirane & 120 & 15 & 98 \\
4 & 2,3 -dimethyl oxirane & 80 & 24 & 25 \\
5 & trams-stilbene oxide & 80 & 120 & 0 \\
\hline
\end{tabular}

"Epoxide $9.5 \mathrm{mmol}$. [DDMIm]I $1.25 \mathrm{mmol}$. and $\mathrm{ZnI}_{2} 0.03 \mathrm{mmol}$
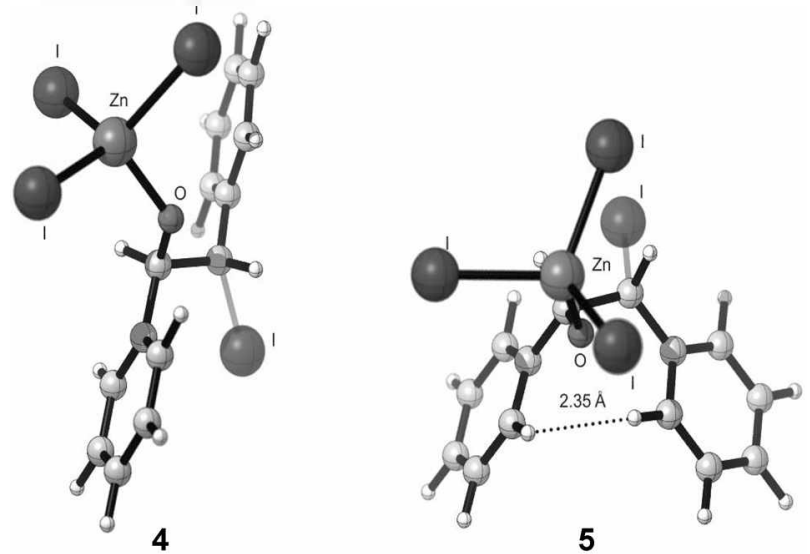

Figure 2. Optimized structures of the intenmediates after ring opening.

their reaction with iodide ion followed by rearrangement were theoretically investigated at the BP86 level of the theory (TZP/DZP basis) using Amsterdam Density Functional (ADF) program. The optimized structures of cis-stilbene oxide (1). trans-stilbene oxide (2) and $\mathrm{ZnI}_{4}{ }^{--}(3)$ are shown in Figure 1. Energetically cis-and trans-stibene oxides are almost same. When epoxide ring is opened by the attack of the iodide ion assisted by coordination of oxy'gen to Lew is acidic Zn(II), cis-stilbene oxide complex (4) becomes less stable than trans-stilbene oxide complex (5) by $3.5 \mathrm{kcal} / \mathrm{mol}$ because two phenyl rings are now in gauche conformation (Figure 2). The internediate $\mathbf{5}$ is calculated to be more stable than the reactants 1 and $3 \mathrm{by} 7.9 \mathrm{kcal} / \mathrm{mol}$. because of the release of the ring strain and the stabilization the negative charge on the oxygen by coordination to $\mathrm{Zn}$ (II). For the rearrangement reaction to take place. $60^{\circ}$ rotation around $\mathrm{C}$. C bond should occur. In case of $(7)$-stilbene oxide this

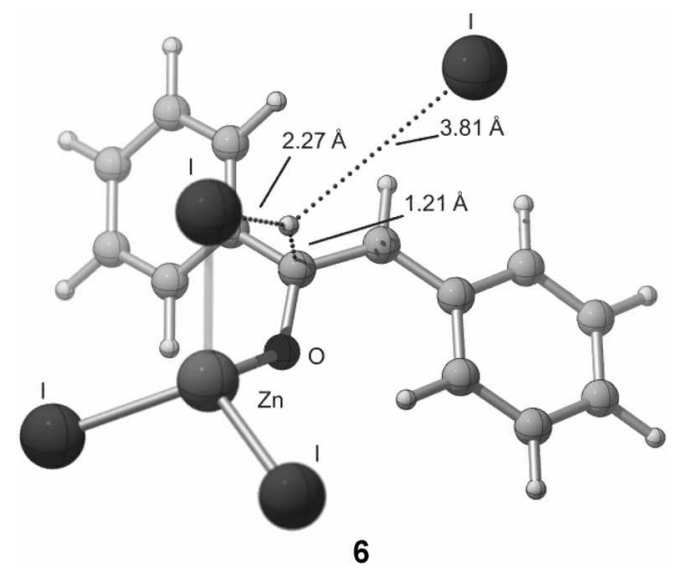

Figure 3. Optimized structure of the transition state.

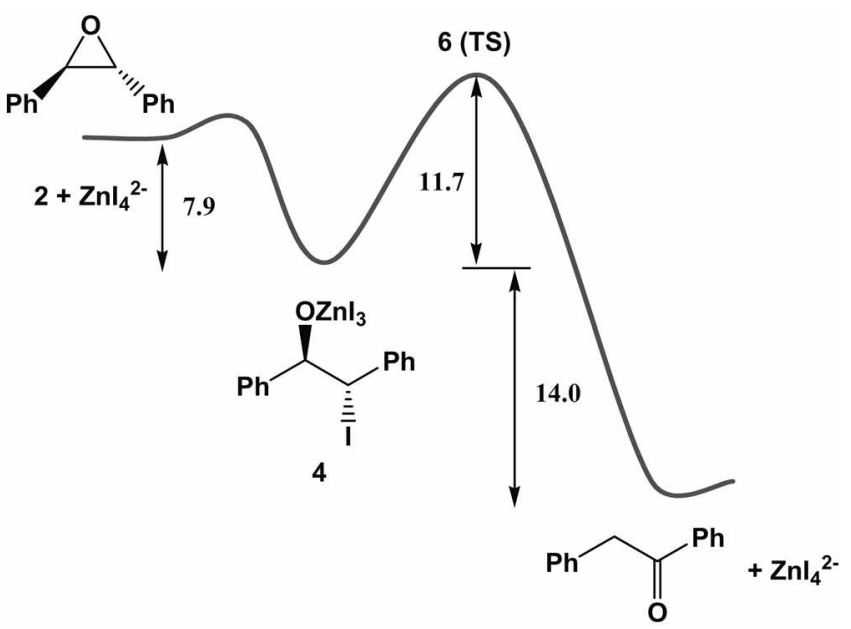

Figure 4. Potential energ surface for the rearrangement reaction. Energies in $\mathrm{kcal} / \mathrm{mol}$.

rotation puts two phenyl groups in eclipsed conformation. This might be the main reason for the inactivity of cisstilbene oxide toward rearrangement under our reaction condition. For the trans-stilbene oxide complex, the removal of hydrogen iodide seems to be the rate-limiting step with the activation energy of $11.7 \mathrm{kcal} / \mathrm{mol}$. This removal process is assisted by the another iodide ion coordinated to $\mathrm{Zn}$ (II) as shown in the structure of the transition state (6) in Figure 3. In the transition state. the iodide ion is almost completely dissociated. while the proton is still close by possibly interacting with the developing C-C double bond. As a whole. the reaction is calculated to be exothemic by $21.9 \mathrm{kcal} / \mathrm{mol}$. 
In conclusion. we were able to selectively rearrange transstilbene oxide to deoxybenzoin using $\mathrm{Zn}$ (II) and ionic liquid as a catalyst under relatively mild reaction condition and using computational method we proposed the plausible mechanism for the reaction.

\section{Computational Details}

Stationary points on the potential energy surface were calculated using the Amisterdam Density Functional (ADF) program, developed by Baerends $e t a{ }^{1 i} .12$ and vectorized by Ravenek. ${ }^{13}$ The numerical integration scheme applied for the calculations was developed by te Velde et $a l^{14.15}$ The geometry optimization procedure was based on the method due to Versluis and Ziegler. ${ }^{16}$ The electronic configurations of the molecular systems were described by double- $\zeta$ STO basis sets with polarization functions for the $\mathrm{H}$. $\mathrm{C}$ and $\mathrm{O}$ atoms. while triple- $\zeta$ Slater type basis sets were entoloyed for the I and $\mathrm{Zn}$ atonss. ${ }^{17.18}$ The $1 s$ electrons of $\mathrm{C}$ and $\mathrm{O}$, the $1 s-4 p$ electrons of $\mathrm{I}$, and the $1 s-2 p$ electrons of $\mathrm{Zn}$ were treated as frozen cores. A set of auxiliary ${ }^{19} s . p . d, f$. and $g$ STO functions. centered on all nuclei. was used in order to fit the molecular density and the Coulomb and exchange potentials in each SCF cycle. Energy differences were calculated by augmenting the local exchange-correlation potential by Vosko et $\mathrm{al}^{20}$ with Becke's $\mathrm{s}^{\mathrm{il}}$ nonlocal exchange corrections and Perdew's"2 nonlocal correlation corrections (BP86). Geometries were optimized including nonlocal corrections at this level of theory. First-order Pauli scalar relativistic corrections ${ }^{23.24}$ were added variationally to the total energy for all systems. In view of the fact that all systems investigated in this work show a large HOMOLUMO gap, a spin-restricted formalism was used for all calculations. No symmetry constraints were used.

Acknowledgments. This research was supported by the Kyung Hee University Research Fund (KHU- 20030297).

\section{References}

1. For a review, see Darensbourg. D. I.: Holtcamp. M. W. Coond.
Chent. Ren: 1996.153.155.

2. (a) Richborn. B. In Conprehensive Organic Sinthesis: Trost. B M.: Fleming. I.. Eds.: Pergamon Press: New York. 1991: Vol. 3.p 733. (b) Rickborn. B.: Gerkin. R. M. J. Am. Chem Soc. 1968. 90 . 4193. (c) Stork. G. Schulenberg, J. W. J. Am. Chem. Soc. 1962. 84. 284. (d) Eliel, E. L.: Delmonte. D. W. J. Am. Chem Soc. 1958. 80. 1744. (e) House. H. O. J. Ant. Chem. Soc. 1955. 77. 3070. (f) House. H. O. J. Ant. Chem. Soc. 1955. 77.5083. (g) Vankar. Y. D.: Saksena. R. K.: Bawa. A. Chem. Lett. 1989. 1241.

3. Rickbon, B.: Gerkin. R. M. J. Am. Chem Soc. 1971, 93.1693.

4. (a) Naqvi. S. M.; Horwitz. J. P. Filler, R. J. Am. Chem. Soc. 1957. 79,6283. (b) House. H. O. Org. Synthesis. Coll. Vol. IV, 1973. 375.

5. (a) Kulasegaram. S.: Kulawiec. R. T. J. Org. Chem. 1997. 62 . 6547. (b) Kulasegaram. S.: Kulawiec. R. J. J. Org. Chem. 1994. 59.7195 .

6. Ranu. B. C.: Jana. U. J. Org. Chem. 1998. 63. 8212.

7. Karame. I. Tommasino, M. L.; Lemaire. M. Tetrahedron Lett. 2003. H, 7687 .

8. Procopio. A.: Dalpozzo. R.: De Nino. A.: Nardi. M.: Sindona. G.: Tagarelli. A. Snlent 2004. 2633.

9. Banerjee. M.: Roy. U. K.: Sinha. P.: Roy. S. J. Organontet. Chent. $2005.690,1422$.

10. Anderson, A. M:Blazek, J. M.: Garg. P; Payne, B. J.: Mohan. R S. Tetrahedron Latt. $2000,11,1527$.

11. Baerends. E. J.: Ellis. D. E.: Ros. P. Chem. Phns 1973. 2. 41 ,

12. Baerends. E. J.: Ros. P. Chem. Phys 1973. 2.52.

13. Ravenek. W. Algorithms and Applications on Tector and Parallel Computers: te Riele. H. J. J., Dekiker, T. J., van de Horst. H. A., Eds.: Elsevier: Amsterdam, The Netherlands. 1987.

14. Velde. G. Baerends. E. J. J. Comput. Chem. 1992.99. 84.

15. Boerrigter. P. M.: Velde. G. t.: Baerends. E. T. Int. J. Qnontm Chent 1988. 33. 87

16. Versluis. L.: Ziegler. T. J. Chent. Phns. 1988. 88. 322.

17. Snijders, J. G.: Baerends. E. J.: Vernoijs, P. At. Nial. Data Tables 1982. 26,483

18. Vernoijis, P.: Snijders, J. G.; Baerends, E. J. Slater Type Basis Functions for the Whole Periodic System. Internal Report (in Dutch): Department of Theoretical Chemistry. Free University: Amsterdam. The Netherlands. 1981.

19. Krijn, J.: Baerends. E. J. Fit Functions in the HFS Method, Internal Report (in Dutch): Department of Theoretical Chemistry. Free University: Amsterdam. The Netherlands, 1984.

20. Vosko. S. H.: Wilk. L.: Nusair. M. Cam. J. Phns. 1980. 58.1200

21. Becke. A. Phs. Rev A 1988. 38.3098

22. (a) Perdew. J. P. Phys. Rev: $B$ 1986. 34. 7406. (b) Perdew. J. P. Phus. Rev $B$ 1986, 33.8822

23. Snijders, J. G.: Baerends. E. J. Hol. Plys. 1978. 36, 1789.

24. Snijders, J. G.: Baerends. E. J.: Ros, P. Mfol. Phus. 1979, 38.1909. 